\title{
MASS MEDIA AND BIOTECHNOLOGY: KNOWLEDGE GAPS WITHIN AND BETWEEN EUROPEAN COUNTRIES
}

\author{
Heinz Bonfadelli
}

\begin{abstract}
Over the past 30 years, many studies have documented the existence of knowledge gaps in a variety of public affairs and science topics and have tried to get a better understanding of how third factors mediate the development of knowledge gaps on the micro level. But there still is almost no comparative research on the macro level. The aim of this study is to analyze education and media based knowledge gaps in the field of biotechnology across 12 European countries and across time. Our data is based on two representative and comparative Eurobarometer surveys carried out in 1996 and 1999 . The results reveal that education and media input are important factors operating not only on the individual level, but also on the country level.

Media effects research was dominated for a long time by a focus on purposeful short-term persuasion of opinions, attitudes, and behavior. The key question was: How can modern mass media be best used to influence political or social behavior in general or acceptance of new technologies like biotechnology in particular. This media-centric perspective dominated until the early i 970 shen long-term cognitive phenomena such as agenda setting, knowledge acquisition, or the cultivation of perceptions and images of the social world became a new focus of media effects research (McCombs, I994, p. 3).

One especially important argument for this paradigm shift was that prior to the process of influencing specific attitudes and behavior-'How do people think about something?'- the objects of attitudes have to be generated, that is the topics or issues have to be 'planted' inside people's heads, on the one hand by personal experience or on the other by mass media information as mediated experience: 'What do people think about?' The public learns about the importance of topics from the emphasis placed upon them by the news media. So the most important effect of mass media may lie in their ability to structure and organize the world for their audiences, based on the journalists gatekeeping routines for selecting, emphasizing, and framing the news. And only on the basis of these cognitive structures will people develop related opinions and attitudes. In
\end{abstract}


addition, the formation of an opinion for or against a new technology-like biotechnology - should be based on a sufficient amount of differentiated knowledge concerning, for example, benefits, risks, and moral judgments formed from a political standpoint, rather than merely reflecting the persuasive efforts of mass media propaganda.

The study of cognitive phenomena like agenda setting or information transfer and learning by mass media is of special interest in the domain of new and complex technologies and the risks associated with them. Biotechnology, as a prominent example, is a very complex and abstract matter and far from most people's personal experience. Thus, information about science and technologies is to a great extent only accessible from modern mass media. Several studies of media use demonstrate the importance of media as sources for technology-related information (e.g., Wade \& Schramm, I969; Robinson, I972; Griffin, I990), especially in the field of risk perception (e.g., Mazur, I98I; Coleman, I993; Dunwoody \& Peters, I992).

\section{THE KNOWLEDGE GAP PERSPECTIVE}

\section{The Basic Hypothesis}

In I970, Phillip J. Tichenor, George A. Donohue, and Clarice N. Olien, researchers at Minnesota University, formulated their 'knowledge gap hypothesis' in a programmatic article entitled 'Mass Media Flow and Differential Growth in Knowledge'. In its initial version, the hypothesis stated: 'As the infusion of mass media information into a social system increases, segments of the population with higher socio-economic status tend to acquire this information at a faster rate than the lower status segments, so that the gap in knowledge between these segments tends to increase rather than decrease' (Tichenor et al., I970, p. I59-160).

The knowledge gap hypothesis questions the normative assumptions about the positive information functions of mass media in democratic societies by confronting it with empirical evidence about the chronically uninformed public. As a consequence, time-related questions about information diffusion in society are connected with social-structural premises: The underlying assumption is that a mere increase of information will not result automatically in a better and equally informed public. On the contrary, the better educated segments of society are able to use the media more efficiently than the less educated, therefore they take advantage of the abundant media information at hand. And as a result, knowledge gaps between the different social segments will increase rather than decrease.

In the last 30 years, more than roo empirical studies in the USA, but also in Europe, have dealt with a broad range of knowledge gap phenomena and have stimulated further theoretical elaborations and refinements (Bonfadelli, I994; 
Gaziano \& Gaziano, 1996; Viswanath \& Finnegan, I996; Kwak, I999). The knowledge gap hypothesis is supported by a variety of empirical studies: Numerous survey studies — mostly not longitudinal—report significant knowledge gaps in the form of correlations between education and/or social status on the one hand and knowledge levels about political matters in general, and especially science, technology, and health related items, on the other hand. But there are inconsistencies, too. Several panel studies report narrowing as well as stable knowledge gaps over time (Bonfadelli, 1994).

\section{From Deficits to Differences and Contingencies}

Two rival explanations were formulated to address these inconsistent empirical results. Traditional proponents of the knowledge gap hypothesis regard motivational factors as secondary, that is to say: as dependent on education and without explanatory power. As a consequence, people with low SES and/or a limited educational background are seen as disadvantaged because of a lack of cognitive resources necessary for knowledge acquisition. One may call this interpretation a deficit model. Other researchers such as Genova and Greenberg (I 979) or Ettema and Kline (I977) instead treat education and motivationfor example interest in an issue or degree of concern-as independent factors in the process of acquiring media information, and try to prove that differential levels of interest and motivation rather than education are crucial for the development of knowledge gaps. This may be called a difference model, which only allows for horizontal distinctions between different social groups in a society. Consequently some researchers (e.g. Horstmann, I99I) regard the knowledge gap hypothesis as not supported or even falsified by empirical research.

Taken together (see Figure I), these two rival explanations suggest a third, a contingency model (Kwak, I999) that rests on the assumption that the emergence of education-based knowledge gaps will be moderated in many situations by motivational factors. Viswanath, Kahn, Finnegan, Hertog, and Potter (I993, p. 559) describe this complex multifactorial setting in the following way: 'In our view, the issue is not motivation or education; it is motivation and education as they operate jointly to affect knowledge.' For example, only moderate knowledge gaps are to be expected in situations with conflict on the macro level of society or high general thematic motivation on the micro level of the individual. But political interest alone without a minimum of cognitive resources, for example in the form of preexisting knowledge and schemata, seems not to be enough to stimulate information seeking and knowledge gain in many situations. Therefore it is the task of empirical research to study how cognitive factors like education or preexisting knowledge as well as motivational factors like personal interest work together in specific situations. 
FIGURE I Rival explanatory models of knowledge gap phenomena

Deficit models:

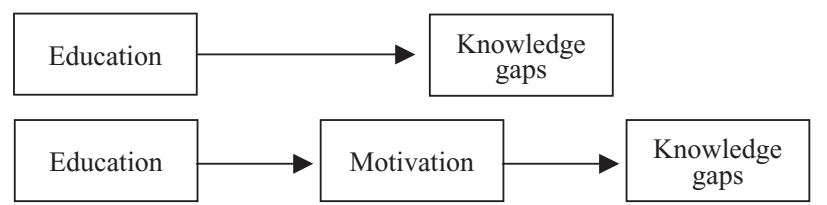

Difference model:
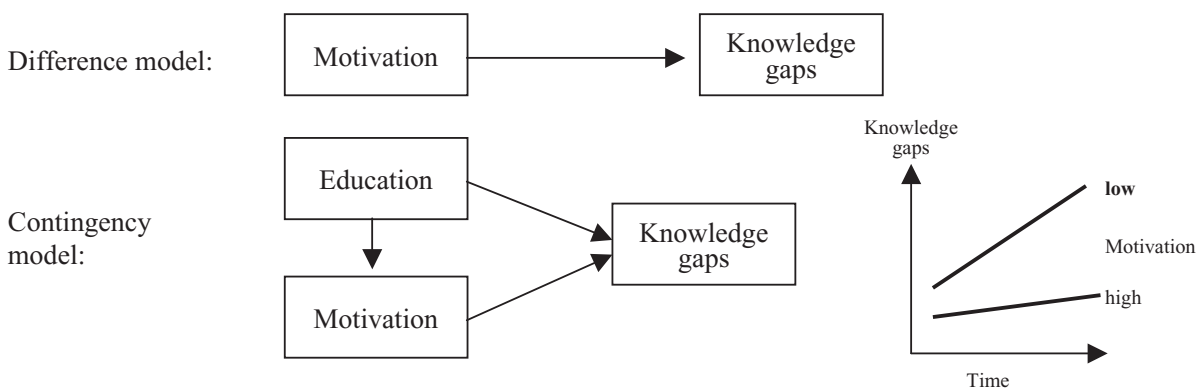

\section{Mediating Processes and Factors}

In recent years, the basic knowledge gap hypothesis has been specified by a variety of contingent conditions and factors mediating between mass media information on the one hand and the audiences on the other hand (Bonfadelli, I994). Donohue, Tichenor, and Olien (1975) refined their initial knowledge gap hypothesis, especially on the macro level, by studying two crucial mediating factors: Gaps tend to be higher and to increase (a) in more pluralistic social settings and (b) when no conflict is involved; whereas gaps are lower and tend to decrease (a) in more homogeneous settings and (b) when conflict is involved (see also Tichenor, Donohue, \& Olien, r980).

Other factors are operating more on the micro level (Ettema \& Kline, I977): Audience related factors are (a) topic specific interest and motivation to seek information actively; (b) communication skills that enable people to manage communication in general and, specifically, to use and interpret media information more effectively (Grabe, 200o); (c) prior knowledge (Price \& Zaller, I993) and underlying cognitive frames (Graber, 200I); (d) access to a variety of information sources and habitualized use of the information-rich print media (McLeod \& Perse, I994); and (e) relevant social contacts and networks functioning as interpersonal communication channels (Viswanath, Kosicki, Fredin, \& Park, 2000). Message related factors are: (a) knowledge topic (e.g. public affairs, health and science vs. human interest); (b) knowledge type (agenda or factual knowledge vs. structural and background knowledge); (c) information channels (newspaper vs. television) or (d) duration (short vs. long time) and intensity of topic-specific media publicity (high vs. low) over time. 


\section{KNOWLEDGE GAPS AND BIOTECHNOLOGY: QUESTIONS AND HYPOTHESES}

Based on the above refinements and considerations, several research questions or hypotheses can be formulated and applied to information diffusion concerning biotechnology on the level of the single individual, but on the country level, also, since the Eurobarometer surveys include knowledge questions and collect information about education and social status as well. Since the surveys were carried out in a similar way in 12 European countries, there is a unique chance for comparisons on the macro level across countries. Furthermore, it is possible to analyze the development of knowledge gaps over time, since there are two measurements: The first survey was carried out in 1996 and the second three years later in I999. This is of special interest, because 'Dolly', the very controversial and thus much covered media event, happened in February 1997.

The focus of this paper relies on the following questions and/or hypotheses:

I. Knomledge across topics and time: How much and what kind of knowledge do people acquire via the mass media in the field of modern biotechnology and genetic engineering? Is it homogeneous across different knowledge items? And: How is this knowledge developing over time between 1996 and I999?

2. Knomledge gaps across social segments and between countries: How homogeneous is the knowledge level of biotechnology on the micro level across various social segments, like men and women, young and old people, different educational segments and varying levels of religiosity or technological optimism. According to the knowledge gap hypothesis, the societal distribution of knowledge is expected to be heterogeneous, and the educational gaps should be far stronger than gaps in gender, age, religiosity, or technological optimism. Moreover, levels in knowledge are expected to vary according to the educational levels of the countries.

3. Communication gaps: There is not only a correlation between education and knowledge on the macro level of the I 2 countries; but it is hypothesized that interpersonal communication and the reception of media information about biotechnology correlate with education as well. According to the knowledge gap hypothesis, people with a higher educational background will talk more frequently and will have heard more about biotechnology in the media than people with a low educational background. Furthermore, the relationship between education and media as information sources will be stronger for print media than for television. And on the macro level, the amount of interpersonal communication as well as media input will be higher in countries with more educated people.

4. Deficits, differences or contingencies: The deficit interpretation of the knowledge gap paradigm rests upon the assumption that education is the crucial 
factor determining knowledge acquisition, although education functions as a motivational factor, too, and thus enhances interest in topics that are abstract and not of immediate personal interest, such as biotechnology. Contrary to this view, motivation rather than education is crucial in the difference paradigm. And the contingency model would expect strong knowledge gaps in the less interested segments, but only weak ones in the very interested segments.

5. Knowledge gaps across countries and time: Most knowledge gap research is focused on the micro level and based on specific social settings. There are only a few studies that are comparative on a macro level across different societal settings. The Eurobarometer survey gives a unique opportunity to compare countries with different levels of education on the macro level. According to the knowledge gap hypothesis there should not only be knowledge gaps across educational segments within countries, but also across countries due to the fact that there are marked differences in the educational levels of different countries. Southern European countries especially_for example Portugal, Spain, Greece, or Italy-have lower educational levels compared to their more industrialized northern counterparts. Furthermore, knowledge gaps should be more pronounced in countries with a higher level of media coverage of biotechnology when compared to countries with a lower level of media input. And across time, knowledge gaps should have increased more in countries where increases in the media coverage of biotechnology were large.

\section{METHODS}

\section{SAMPLES}

The data presented are based on two Eurobarometer surveys, carried out in the winters of 1996 (Durant, Bauer, \& Gaskell, I998) and I999 (Gaskell \& Bauer, 200I) in I 7 European countries with representative samples of I,ooo people, I 5 years and older in each country, and two similar surveys carried out in the USA and Canada. Besides these surveys, our analysis is based on a comparative longitudinal content analysis of the press coverage of biotechnology between 1992 and I999. Results are presented for I 2 countries, not weighted by population sizes (for details, see Bauer, 2005, in this issue).

\section{MeAsures}

Our knowledge measure is based on nine comparable knowledge questions (true/ false items) concerning biotechnology. They were condensed into an additive knowledge index (with I assigned for every correct answer, o for a false answer or 
don't know). Knomledge gaps are expressed either as absolute differences between the mean knowledge level in the lowest and the highest educational segment, or as simple or partial correlation between mean knowledge and education, controlled for age, sex, religiosity, and technological optimism. Two questions aimed at communication: having talked about modern biotechnology with anyone (interpersonal communication) and having heard anything about biotechnology in the newspapers or on television (reception of media information). Motivation is operationalized as perceived interest in modern biotechnology: 'How important are these issues to you personally?' This question was asked only in the 1996 survey and was measured on a Io-point scale with $\mathrm{I}=$ not at all important and Io=extremely important (see Appendix to Bauer, 2005, in this issue, for question wordings).

\section{RESULTS}

\section{Structure and Development of Biotechnology Knowledge}

Table I shows that, on average, people in Europe gave about five correct answers to the nine knowledge questions. This equals a total knowledge of about 55 percent. The mean knowledge index was quite stable over time and rose only slightly from 4.9 to 5 .o between 1996 and 1999 . On the other hand, media coverage of biotechnology increased by a factor of more than four from the period of I 992-96 to I997-99 (see Table 3). The only statement with a strong and significant increase in correct answers over time, from 47 percent in 1996 to 65 percent in I999, referred to the heavily publicized topic of cloning: 'The cloning of living things produces exactly identical offsprings.' Interestingly, the knowledge level in the USA and Canada seems to be about ro percent higher than in Europe.

Even if three of the nine items - the existence of bacteria living from waste water, Down's syndrome being detectable during pregnancy, and yeast consisting of living organisms - were answered correctly by large majorities of the interviewed persons and another three questions by about half of them, there seems to be a lot of uncertainty and false knowledge, especially concerning matters of modern genetic engineering. Only about one in three people know that ordinary tomatoes also contain genes, that genetically modified animals need not always be bigger than ordinary ones, or that animal genes can be transfered to plants.

Taken together, the average knowledge level in the field of modern biotechnology of the population in Europe has to be described as modest and as significantly lower than in the USA and Canada. Besides these limitations on acquiring, processing and storing science-related information provided by the mass media (see Graber, 200I), there is also incomplete and inaccurate recall of this information. Many people did not acquire the necessary science literacy at school and are thus unable to make the necessary linkages and interpretations. As 


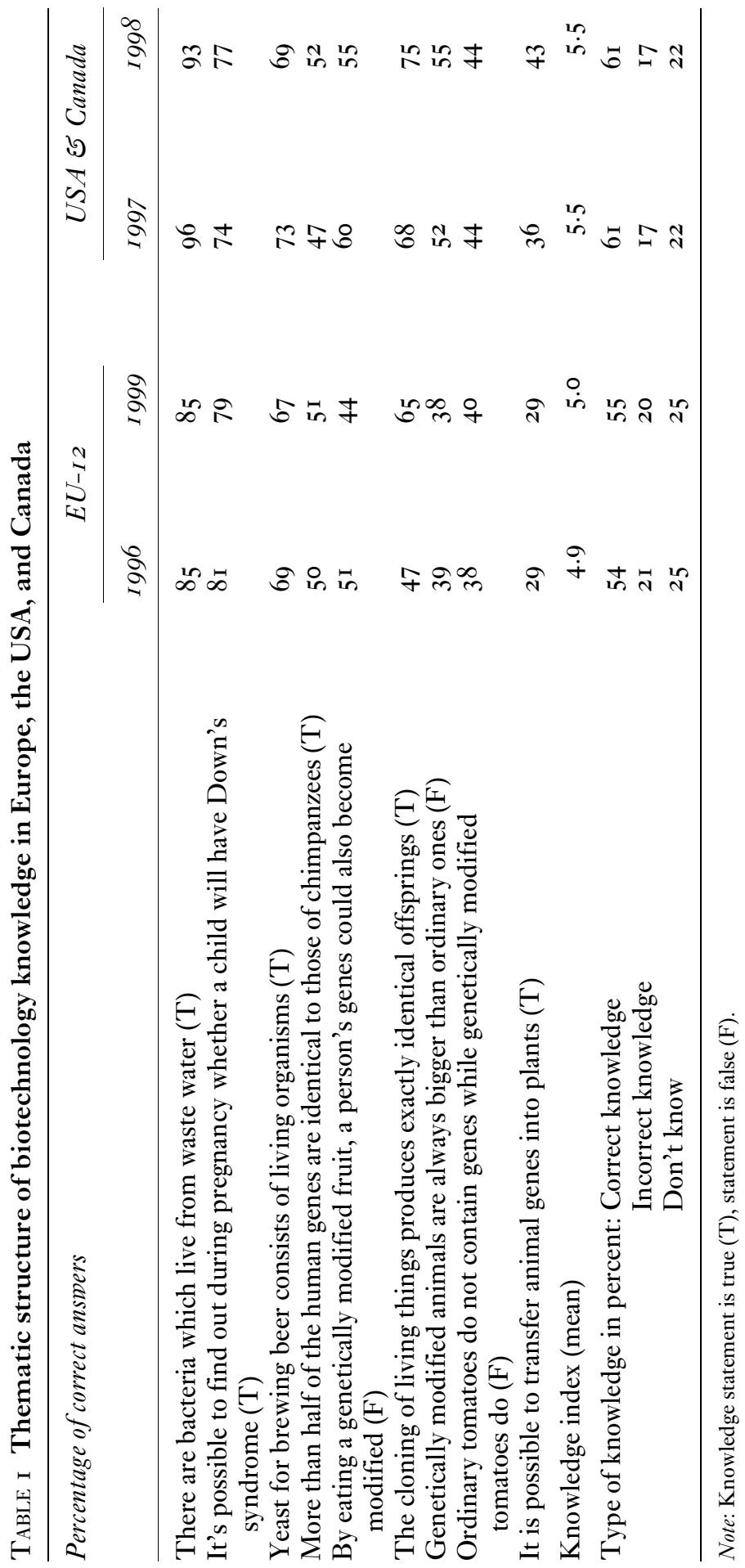


a result, besides the 25 percent 'don't know' answers given in 1999, there are another 20 percent explicitly incorrect answers.

\section{Knowledge Levels Across Social Segments and Between Countries}

On the micro level (see Table 2), the distribution of knowledge in biotechnology is not at all homogeneous. Men, younger, more educated and non-religious people with positive attitudes towards modern technologies are better informed, and the pattern is roughly the same in the two surveys. The comparison of the simple with the partial correlations shows that the knowledge gaps between educational segments of the society remain strong, which is in line with the knowledge gap hypothesis, while the gaps concerning religiosity and technological optimism appear a little bit smaller-but still relevant-than for the simple correlations. Contrary to that, the gaps between the gender and age groups almost vanish when partial correlations are considered. Apparently, most of the gender and age differences in knowledge have to be attributed to the fact that the educational

TABLE 2 Gaps in biotechnology knowledge across social segments

\begin{tabular}{|c|c|c|c|c|c|c|c|}
\hline \multirow{3}{*}{\multicolumn{2}{|c|}{$\begin{array}{l}\text { 9-item } \\
\text { knomledge } \\
\text { index }\end{array}$}} & \multicolumn{3}{|c|}{ I996 } & \multicolumn{3}{|c|}{1999} \\
\hline & & \multirow[b]{2}{*}{ Means } & \multicolumn{2}{|c|}{ Correlations } & \multirow[b]{2}{*}{ Means } & \multicolumn{2}{|c|}{ Correlations } \\
\hline & & & Simple & Partial & & Simple & Partial \\
\hline Total & & 4.9 & & & 5.0 & & \\
\hline \multirow[t]{2}{*}{ Sex: } & Men & $5 \cdot \mathrm{I}$ & & & 5.2 & & \\
\hline & Women & 4.7 &.$+ \mathrm{IO}$ & +.03 & 4.8 &.$+ \mathrm{I} I$ & +.04 \\
\hline \multirow[t]{4}{*}{ Age: } & $55^{+}$years & 4.2 & & & $4 \cdot 3$ & & \\
\hline & $40-54$ years & 5.0 & & & $5 \cdot \mathrm{I}$ & & \\
\hline & 25-39 years & $5 \cdot 3$ & & & $5 \cdot 4$ & & \\
\hline & I 5-24 years & $5 \cdot 4$ & $-.2 \mathrm{I}$ & -.07 & $5 \cdot 4$ & -.20 & -.03 \\
\hline \multicolumn{2}{|c|}{ Education: High } & $5 \cdot 9$ & & & 5.8 & & \\
\hline & Medium & 4.9 & & & 4.9 & & \\
\hline & Low & 3.8 & +.39 & +.32 & 3.9 & +.35 & +.29 \\
\hline \multicolumn{2}{|c|}{ Religiosity: Very religious } & $4 . I$ & & & 4. I & & \\
\hline & Somewhat & 4.7 & & & 4.8 & & \\
\hline & Neither/nor & 5.2 & & & $5 \cdot 3$ & & \\
\hline & Not at all & $5 \cdot 5$ & -.22 & -.14 & $5 \cdot 5$ & $-.2 \mathrm{I}$ & -.12 \\
\hline \multicolumn{8}{|c|}{ Technological optimism: } \\
\hline & High & 5.2 & & & $5 \cdot 4$ & & \\
\hline & Medium & 5.2 & & & $5 \cdot 3$ & & \\
\hline & Moderate & 5.0 & & & 5.0 & & \\
\hline & Low & $4 \cdot I$ & +.20 & +.14 & 4. I & +.24 & +.I 8 \\
\hline
\end{tabular}

Note: Simple Pearson correlations and partial correlations controlled for the other four sociodemographic variables. $N=$ ca. 12,000 . 
level of women and older age groups is still lower than that of men and younger people, and to the fact that older people and women are more religious than men and the young.

Table 3 displays knowledge levels and knowledge gaps across countries for I999 and trends between I996 and I999 for knowledge levels and knowledge gaps in percentages on the basis of 1996 (= Index I00). Education-based knowledge gaps can be operationalized and measured (a) as differences of the mean knowledge levels of the highest and lowest educational segment or (b) as correlations between knowledge and education.

Knowledge levels vary strongly between the different countries, with northern European countries such as Denmark, Finland, the Netherlands and Sweden, but including Switzerland, showing higher levels than southern countries such as Italy, Greece, and Portugal. There is a high correlation of rho $=.85$ in 1996 , resp. rho $=.8 \mathrm{I}$ in 1999 , between the educational ranking of the countries and the mean levels of knowledge. But there are also some outliers (Figure 2). Sweden and the Netherlands, and the UK as well, have knowledge levels significantly above what would have been expected given their educational ranking.

The question of how to measure the educational status of a person in a comparable way across countries is certainly a methodological problem. The Eurobarometer uses the question: 'How old were you when you stopped full-time education?' There are two inherent problems: Primary school starts at different ages in different countries, and the required number of years of obligatory schooling varies also. A third problem is how to handle people still in education when interviewed. As a result, other educational rankings of countries exist. For instance, OECD statistics give a slightly dissimilar picture, with higher values, especially for the UK and Germany, than the Eurobarometer shows.

In general, knowledge levels increased slightly in 8 of the $\mathrm{I} 2$ countries. But there are some marked exceptions too: The overall knowledge levels decreased in Switzerland and the UK (-I I percent), countries with especially high knowledge levels in I996. Increases were largest in Greece (+I9 percent), Austria (+I6 percent), and Sweden (+ I I percent). There seems to be no consistent pattern between an increase in knowledge and an increase in the intensity of media coverage. One explanation could be that knowledge was measured mainly in the form of textbook knowledge and without clear reference to media information about topical issues in biotechnology, such as cloning.

Interpersonal Communication and Information by Mass Media Across Countries

Not only knowledge, but interpersonal communication and mass media information also vary with the educational levels of the European countries. Thirty-seven percent of respondents across Europe had occasionally or even frequently talked 


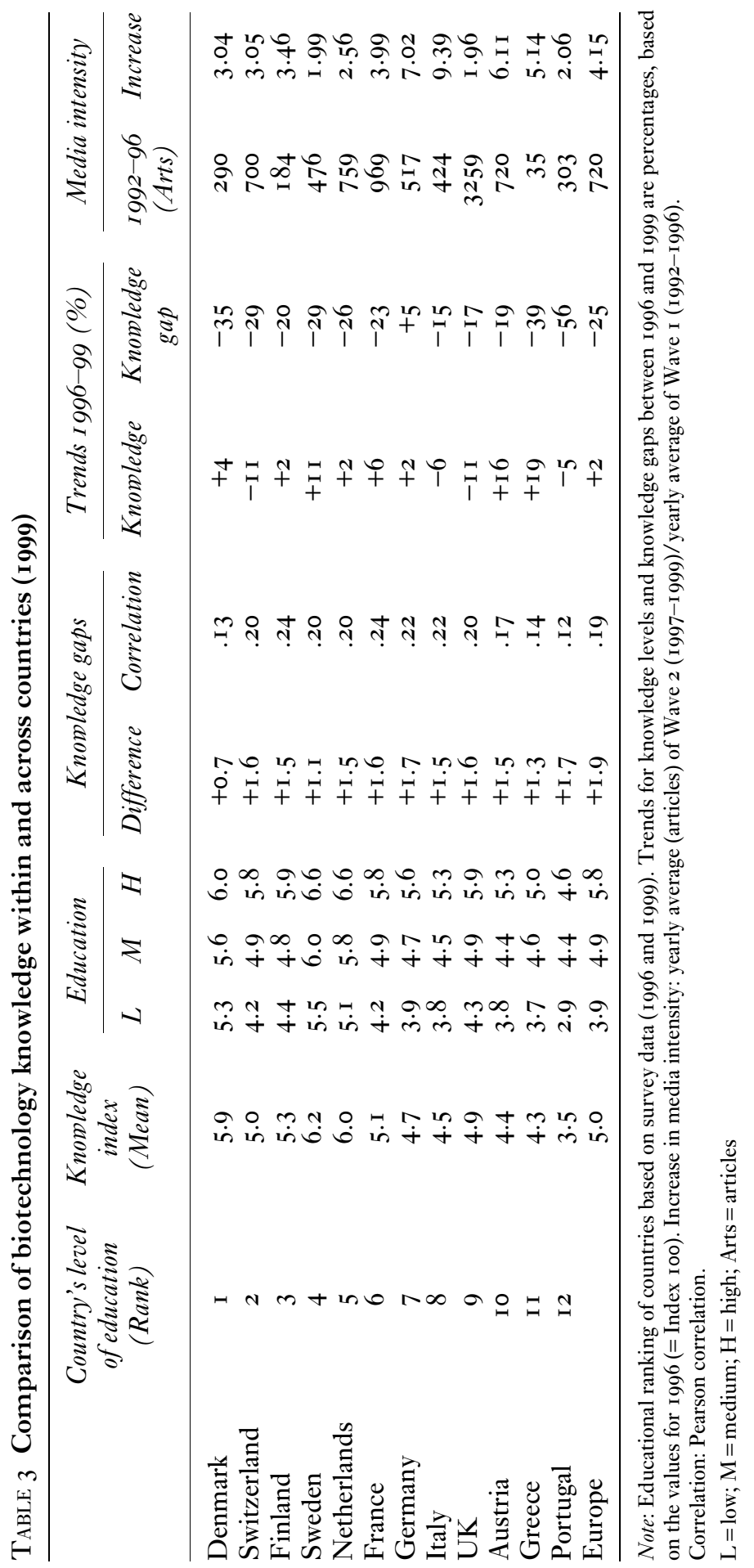


FIGURE 2 Country knowledge levels by country education level

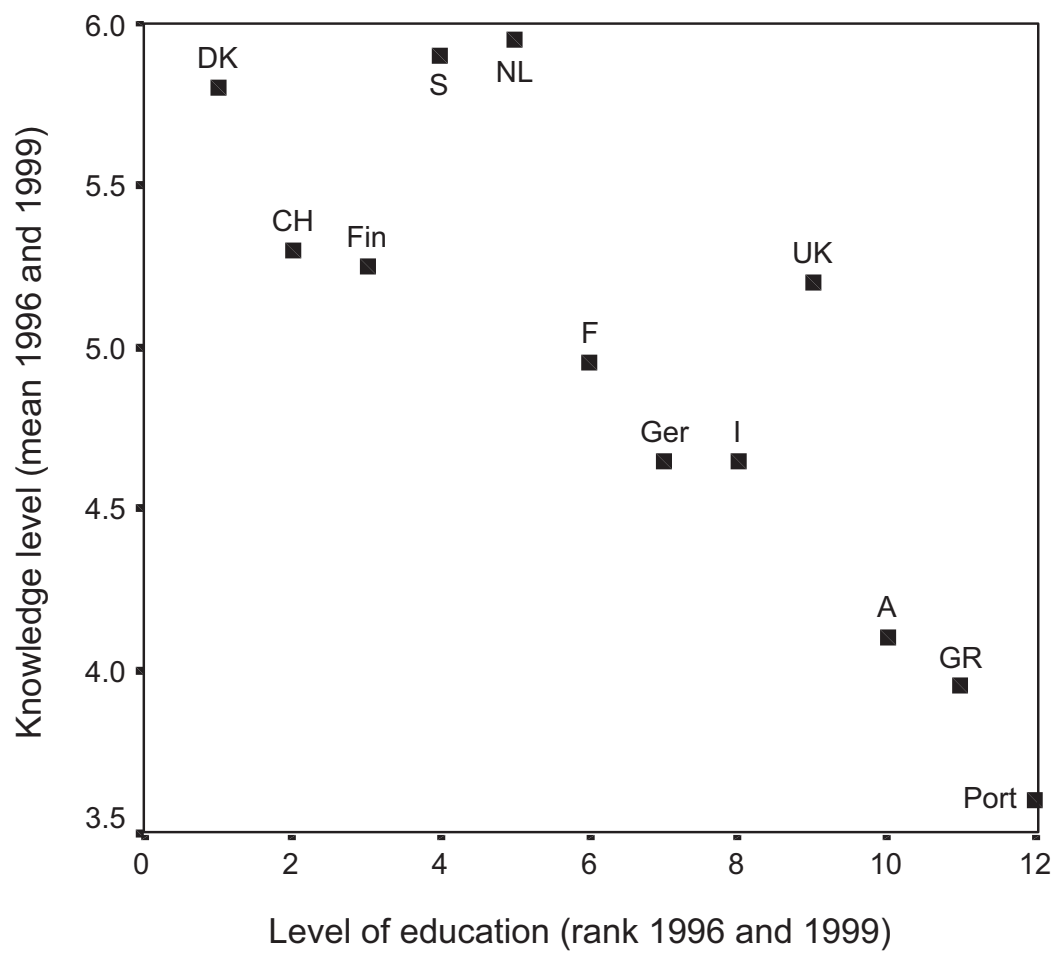

about modern biotechnology with someone before the 1996 survey, and 34 percent reported the same in I999. The correlation between intensity of interpersonal communication and the educational level of the countries is rho $=.77$ resp. rho $=.73$. And, in 1996,57 percent had heard something in the mass media about issues involving modern biotechnology over the last three months before the survey; 38 percent in television and 35 percent in the press (newspapers or magazines). The correlations between mass media and educational rank of the countries is rho $=.6 \mathrm{I}$. Figure 3 illustrates the relationship of the level of education in a country and the occurence of interpersonal communication, while Figure 4 illustrates the level of education with the reception of mass media information on biotechnology.

These general patterns are certainly mediated by third factors and modified by special circumstances, as for example in Switzerland. The national referendum that took place there on June 7 , I998, stimulated very intensive mass media coverage of biotechnology, and the highly controversial public debate initiated many interpersonal discussions about the topic. 
FIGURE 3 Interpersonal communication about biotechnology by country educational level

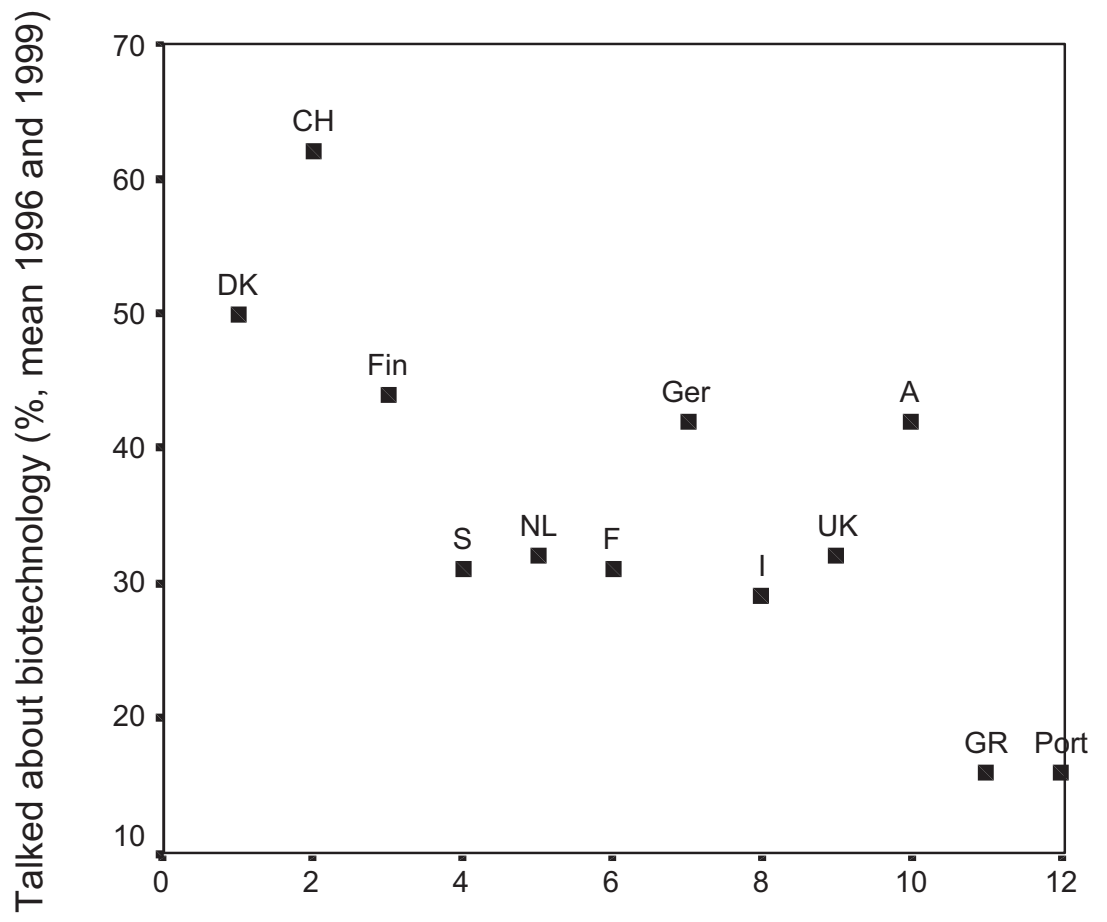

Level of education (rank 1996 and 1999)

\section{Deficits, Differences or Contingencies?}

There is a significant, but weak correlation between personal interest in biotechnology and level of education $(\mathrm{rho}=. \mathrm{I} 7)$. This means that modern biotechnology is perceived as personally more important by people with a higher educational background. The mean level of interest in the low education group of 6.4 points increases by about 15 percent to 7.3 points in the high education group on a Io-point scale. As a consequence, the strong knowledge gap between educational groups decreases slightly if one controls for age, sex and relevance, with correlations decreasing from rho $=.39$ to $.3 \mathrm{I}$. In comparison, the motivational gap $(\mathrm{rho}=.20$, resp. rho $=.15)$ is clearly weaker.

To summarize, there is no evidence for a difference interpretation of knowledge gaps in the field of biotechnology, nor for a contingency interpretation. Instead, education and motivation are working separately in the same direction: people who think that biotechnology is important for them have a knowledge level I.o point higher than people with no interest in biotechnology. And otherwise, 
FIGURE 4 Reception of mass media information on biotechnology by country educational level

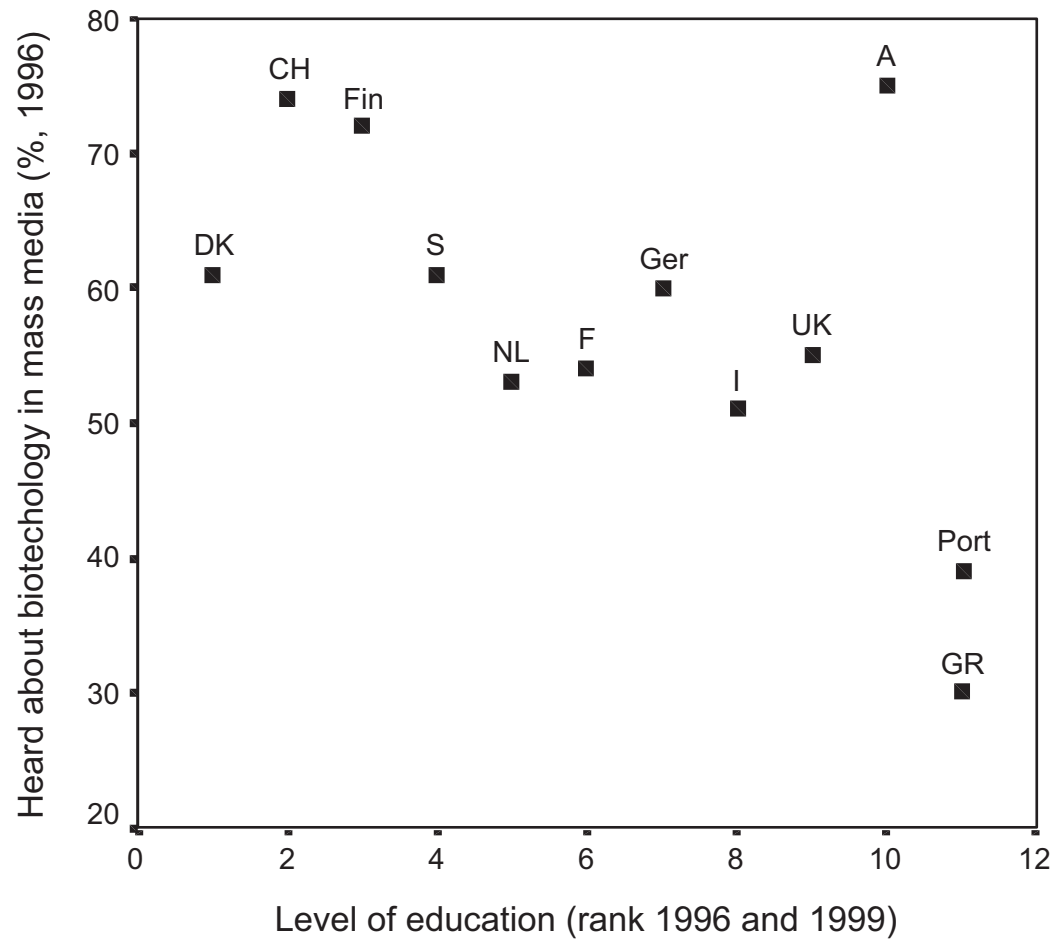

there is no indication of lower knowledge gaps in the highly motivated segments. The impact of education on knowledge compared to that of motivation (both expressed as partial correlations) is significantly stronger, namely rho $=.3 \mathrm{I} \mathrm{com-}$ pared to rho $=$. I 5 (Table 4$)$.

\section{Mass Media and Knowledge in and across Countries}

People can learn about biotechnology from the media only if they read, see or hear something there. As a consequence, respondents in our survey who remember receiving media information know significantly more about biotechnology than people who had no access to media information on the subject. The mean knowledge score of the segment with media contact is 1.2 points or 29 percent higher than for those without contact (Table 5). The influence of print media is a little bit stronger than television. If one looks at the interaction of media impact and education, the data show a tendency for narrowing gaps: learning effects by access to the media (both print and television) are more pronounced in the less educated than in the highly educated segments. But media effects are significantly 


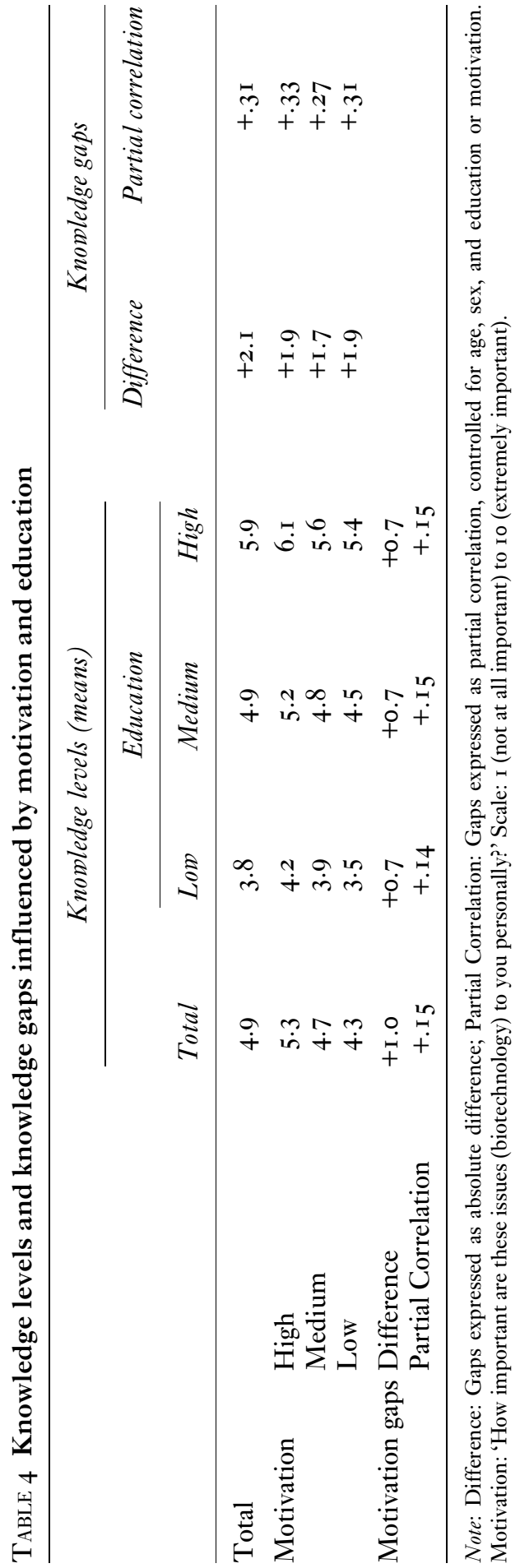


TABLE 5 Knowledge levels by education and mass media information

\begin{tabular}{|c|c|c|c|c|c|c|}
\hline & \multicolumn{4}{|c|}{ Knomledge levels (means) } & \multicolumn{2}{|c|}{ Knomledge gaps } \\
\hline & \multirow[b]{2}{*}{ Total } & \multicolumn{3}{|c|}{ Education } & \multirow[t]{2}{*}{ Difference } & \multirow[t]{2}{*}{ Partial correlation } \\
\hline & & Low & Medium & High & & \\
\hline Total & 4.9 & 3.8 & 4.9 & $5 \cdot 9$ & $+2 . \mathrm{I}$ & $+.3 \mathrm{I}$ \\
\hline Media contact & $5 \cdot 4$ & $4 \cdot 3$ & 5.2 & $6 . \mathrm{I}$ & $+\mathrm{I} .8$ & +.28 \\
\hline No media contact & 4.2 & $3 \cdot 4$ & $4 \cdot 5$ & $5 \cdot 4$ & +2.0 & +.27 \\
\hline General media effect & $+\mathrm{I} .2$ & +0.9 & +0.7 & +0.7 & & +.16 \\
\hline Print media effect & $+\mathrm{I} .2$ & $+\mathrm{I} . \mathrm{O}$ & +0.8 & +0.6 & & +.16 \\
\hline Television effect & $+\mathrm{I} . \mathrm{O}$ & $+\mathrm{I} . \mathrm{O}$ & +0.6 & +0.5 & & +.14 \\
\hline
\end{tabular}

Note: Data for 1996 only. Knowledge gaps: Partial correlations controlled for age, sex motivation, and media contact; partial correlations for media effects controlled for age, sex, motivation, and education.

weaker (partial correlation: .r6) than the effect of educational background (.28). As a consequence, even if people with a lower educational background will learn from the media, that will not be enough to close the gap to their better educated compatriots.

The impact of mass media information on knowledge levels can be seen at the macro level, too. The infusion of mass media information into a country has a significant impact on the overall level of knowledge in that country (see Figure 5), with one significant exception: although 75 percent of Austrians report having heard about biotechnology in the mass media, the mean level of knowledge in this country is still very low.

\section{Knowledge Gaps Across Countries and Time}

Across countries, knowledge gaps vary less than knowledge levels. According to the knowledge gap hypothesis, knowledge gaps should be higher in countries where many people report 'having heard about biotechnology in the media,' as compared to countries where fewer people say this. Figure 6 displays the relationship, using partial correlations between education and level of knowledge in I996, controlled for age, sex, religiousness and technological optimism, as indicators of knowledge gaps.

In general, the data do not support the prediction of the knowledge gap hypothesis very well. Although there are some countries where both knowledge gaps and the frequency of contact with media information are high (Finland, Switzerland, and Sweden), as well as countries where both are low (Greece), there are also clear exceptions like Germany, Denmark, and Austria. In these three countries, more than 60 percent of the population had heard about biotechnology in the mass media, but knowledge gaps are weak. Mediating third factors such as 
FIGURE 5 Knowledge level by reception of media information across countries (1996)

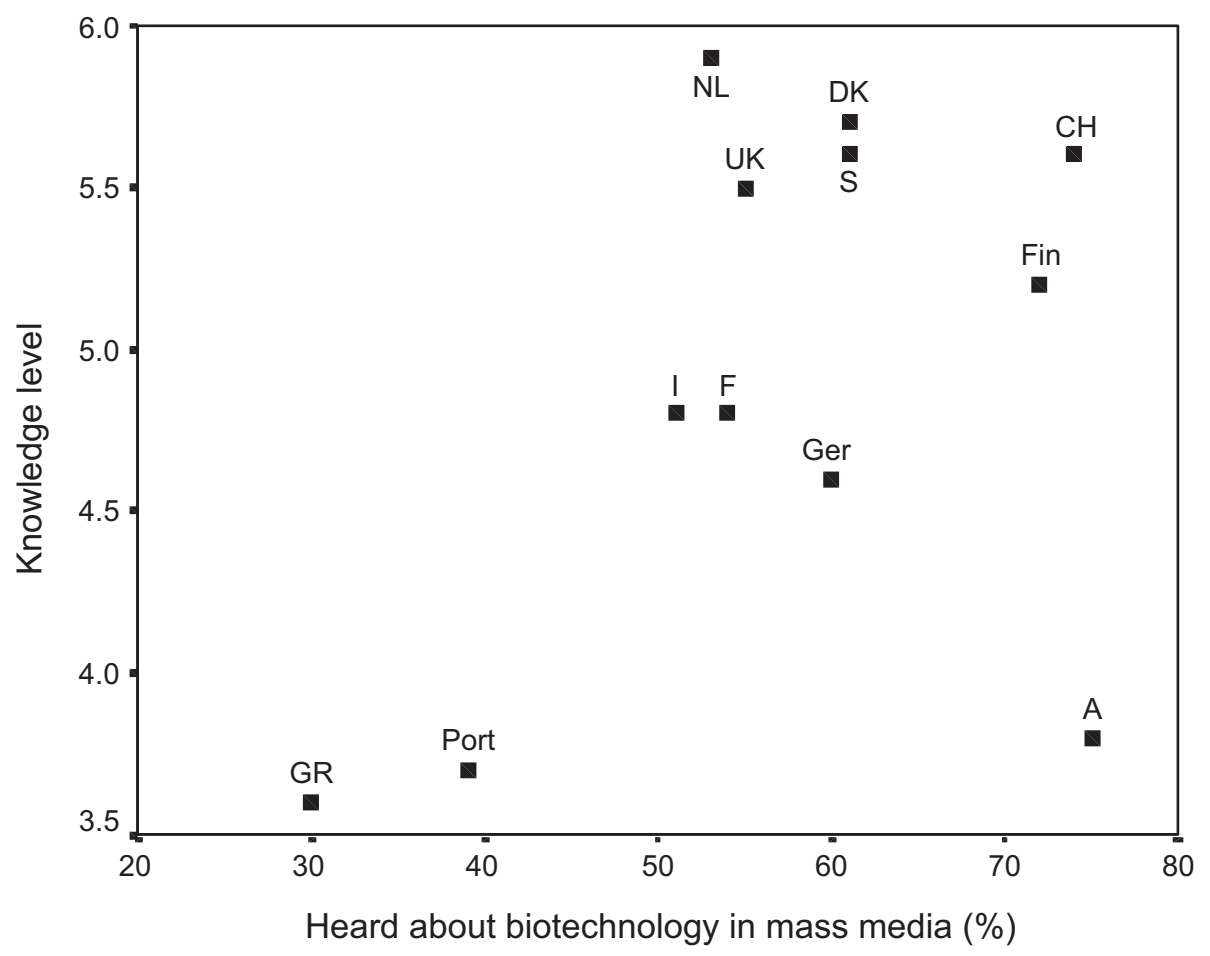

interpersonal communication could explain these exceptions, because frequent discussions of a topic can function as a knowledge leveler. As Figure 6 shows, this mechanism seems to be at work in countries like Germany, Austria, and Denmark, but not in Switzerland or Finland.

The original knowledge gap hypothesis predicts a widening knowledge gap not only between social systems but within a social system: If there is an increase in the flow of media information over time, the knowledge gap should widen. This assumption is not in accordance with our data: There was an increase of media information in the field of biotechnology in every country between 1996 and 1999, while knowledge gaps decreased from 1996 to 1999 in eleven of the twelve countries. But, nevertheless, there is a correlation $(\mathrm{rho}=.48)$ between changes in knowledge gaps and the increase of media information as ascertained by our content analysis in accordance with the knowledge gap hypothesis. That means knowledge gaps declined strongly in countries with only a modest increase in media information, such as Portugal, but rose in a country with a strong increase in available media information, for example Germany (Figure 7). 
FIGURE 6 Knowledge gaps by reception of media information across countries (1996)

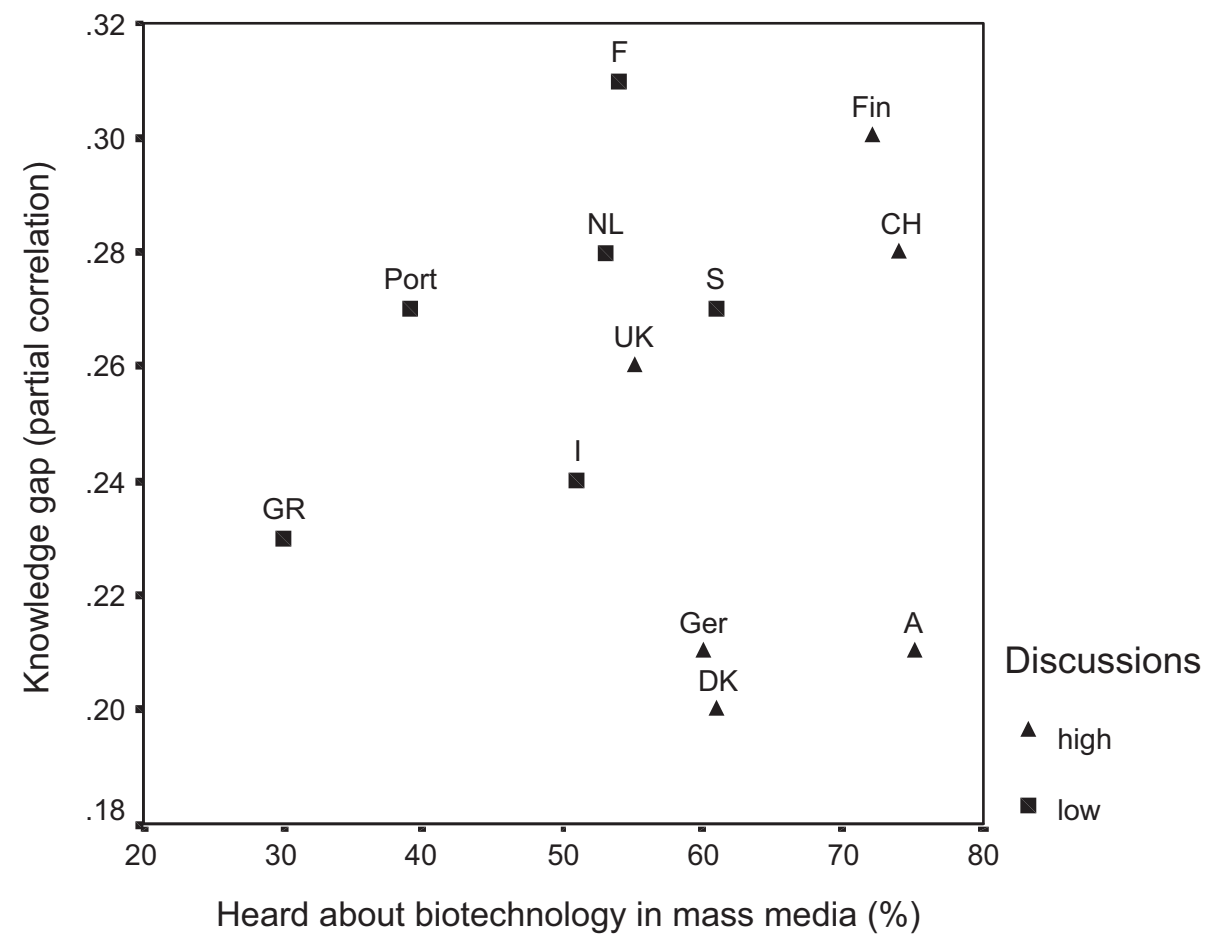

\section{SUMMARY AND CONCLUSIONS}

The analysis of the two Eurobarometer surveys clearly demonstrates that there are not only distinct educational segments within each country, but also pronounced educational differences between the i2 European countries. As a consequence of these differences, knowledge of biotechnology also varies between countries: People in countries with a higher level of education tend to know more about biotechnology than people in countries with a lower level of education. Furthermore there are gaps in interpersonal and mass mediated information between countries: The higher the educational level of a country, the more people talk about and have heard about biotechnology in the mass media. These relationships have significant consequences for the acquisition of biotechnology knowledge: people in countries with high levels of education and with intensive communication, both personal and mass mediated, are more knowledgeable about biotechnology than people in countries with lower levels of education and communication.

Nor do our data correspond with the knowledge gap hypothesis if one looks at the development over time. Contrary to the knowledge gap hypothesis, knowledge 
FIGURE 7 Change in knowledge gaps by increase in amount of media coverage across countries

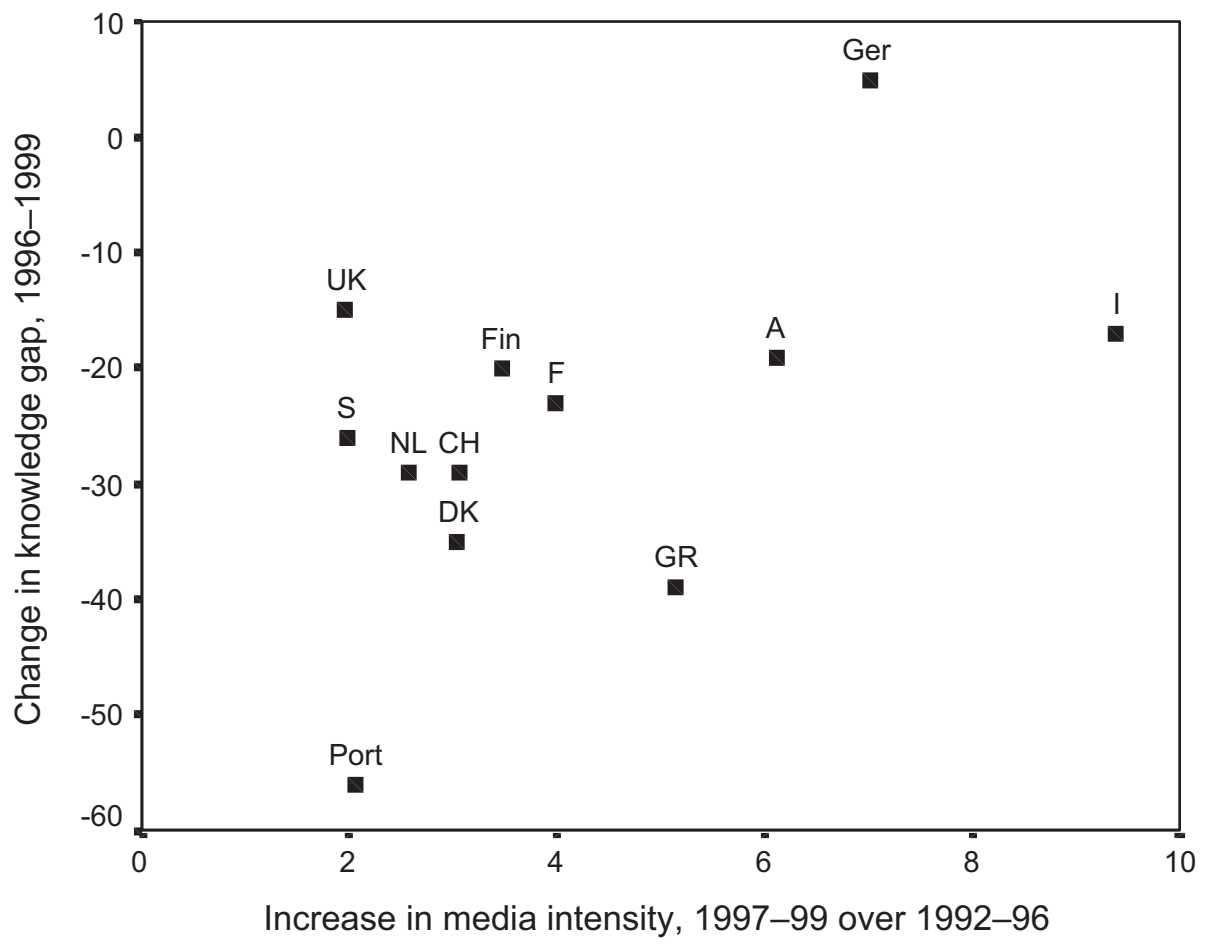

Note: Details of measure on increase in media intensity and change in knowledge gap are given in Table 3.

gaps decreased in most of the countries between I 996 and I999 although the amount of media coverage increased significantly. In part this is certainly due to the textbook-manner measurement of biotechnology knowledge in the Eurobarometer survey, which made very little reference to the coverage of the subject by the mass media. Nevertheless, there is some support for the knowledge gap hypothesis if one compares the increase in the amount of media coverage with the change of knowledge gaps over time: The higher the increase in media coverage, the more likely it was that the existing knowledge gaps at the country level remained.

\section{REFERENCES}

Bauer, M. W. (2005). Public perceptions and mass media in the biotechnology controversy. International Fournal of Public Opinion Research, ${ }_{77}$, in this issue.

Bonfadelli, H. (1994). Die Wissenskluft-Perspektive. Massenmedien und gesellschaftliche Information [The knowledge gap hypothesis. Mass media and social information]. Konstanz: UVK. 
Coleman, C.-L. (I993). The influence of mass media and interpersonal communication on societal and personal risk judgements. Communication Research, 20, 6 I I-628.

Donohue, G. A., Tichenor, Ph. J., \& Olien, C. N. (I975). Mass media and the knowledge gap: A hypothesis reconsidered. Communication Research, 2, 3-23.

Dunwoody, S., \& Peters, H. P. (I992). Mass media coverage of technological and environmental risks: A survey of research in the United States and Germany. Public Understanding of Science, I, I99-230.

Durant, J., Bauer, M. W., \& Gaskell, G. (I999). Biotechnology in the public sphere. A European sourcebook. London: Science Museum.

Ettema, J. S., \& Kline, G. F. (I977). Deficits, differences, and ceilings. Contingent conditions for understanding the knowledge gap. Communication Research, 4, I79-202.

Gaskell, G., \& Bauer, M. W. (200I). Biotechnology I996-2000. The years of controversy. London: Science Museum.

Gaziano, C., \& Gaziano, E. (1996). The knowledge gap: Theories and methods in knowledge gap research since i970. In M. B. Salwen \& D. W. Stacks (Eds.), An integrated approach to communication theory and research (pp. I27-I43). Mahwah, NJ: Erlbaum.

Genova, B. K. L., \& Greenberg, B. S. (1979). Interests in news and the knowledge gap. Public Opinion Quarterly, 43, 79-91.

Grabe, M. E. (2000). Cognitive access to negatively arousing news. An experimental investigation of the knowledge gap. Communication Research, 27, 3-26.

Graber, D. (200I). Processing politics. Learning from television in the Internet age. Chicago \& London: Chicago University Press.

Griffin, R. J. (I990). Energy in the eighties: Education, communication, and the knowledge gap. Fournalism Quarterly, 67, 554-566.

Horstmann, R. (I99I). Medieneinflüsse auf politisches Wissen. Zur Tragfähigkeit der Wissenskluft-Hypothese [Media influence on political knowledge. On the scope and stability of the knowledge gap hypothesis]. Wiesbaden: Deutscher Universitätsverlag.

Kwak, N. (I999). Revisiting the knowledge gap hypothesis. Education, motivation, and media use. Communication Research, 26, 385-4I3.

McCombs, M. (I994). News influence on our pictures of the world. In J. Bryant \& D. Zillmann (Eds.), Media effects. Advances in theory and research (pp. I-I6). Hillsdale, NJ: Erlbaum.

McLeod, D., \& Perse, E. M. (I994). Direct and indirect effects of socioeconomic status on public affairs knowledge. Fournalism Quarterly, 7I, 433-442.

Mazur, A. (I98I). Media coverage and public opinion on scientific controversies. Fournal of Communication, 3I(2), Io6-I I 5.

Price, V., \& Zaller, J. (I993). Who gets the news? Alternative measures of news reception and their implications for research. Public Opinion Quarterly, 57, I33-164.

Robinson, J. P. (I972). Mass communication and information diffusion. In G. F. Kline \& P. J. Tichenor (Ed.), Current perspectives in mass communication research (pp. $7 \mathrm{I}-93$ ). Beverly Hills \& London: Sage.

Tichenor, P. J., Donohue, G. A., \& Olien, C. N. (I970). Mass media flow and differential growth in knowledge. Public Opinion Quarterly, 34, I 59-I 7o.

Tichenor, P. J., Donohue, G. A., \& Olien, C. N. (I980). Community conflict Es the press. Beverly Hills \& London: Sage. 
Viswanath, K., \& Finnegan, J. R. (I996). The knowledge gap hypothesis: Twenty-five years later. In B. R. Burleson (Ed.), Communication yearbook (Vol. I9, pp. I87-227). London: Sage.

Viswanath, K., Kahn, E., Finnegan, J. R., Hertog, J., \& Potter, J. D. (I993). Motivation and the knowledge gap. Effects of a campaign to reduce diet-related cancer risk. Communication Research, 20, 546-563.

Viswanath, K. A., Kosicki, G. M., Fredin, E. S., \& Park, E. (2000). Local community ties, community-boundedness, and local public affairs knowledge gaps. Communication Research, 27, 27-50.

Wade, S., \& Schramm, W. (1969). The mass media as sources of public affairs, science, and health knowledge. Public Opinion Quarterly, 33, 197-209.

\section{BIOGRAPHICAL NOTE}

Heinz Bonfadelli is a professor at the Department of Mass Communication and Media Research, University of Zurich. His research areas include media effects, knowledge gap, digital divide, children, and mass media. Among his recent publications is Medienmirkungsforschung, Vol. I: Grundlagen, and Vol. II: Anwendungen (Media effects research, Vol. I: Basics, Vol. II: Applications), published with UVK, Constance 2004.

Address correspondence to Prof. Dr. Heinz Bonfadelli, IPMZ-Institut für Publizistikwissenschaft und Medienforschung der Universität Zürich, Andreasstrasse I 5, CH-8050 Zürich, Switzerland, e-mail: h.bonfadelli@ipmz.unizh.ch 